\title{
Local Bone Marrow Renin-Angiotensin System and Atherosclerosis
}

\author{
Yavuz Beyazit, ${ }^{1}$ Tugrul Purnak, ${ }^{2}$ Gulay Sain Guven, ${ }^{3}$ and Ibrahim C. Haznedaroglu' \\ ${ }^{1}$ Department of Gastroenterology, Turkiye Yuksek Ihtisas Teaching and Research Hospital, 06100 Ankara, Turkey \\ ${ }^{2}$ Department of Gastroenterology, Ankara Numune Education and Research Hospital, 06100 Ankara, Turkey \\ ${ }^{3}$ Department of Internal Medicine, Faculty of Medicine, Hacettepe University, 06100 Ankara, Turkey \\ Correspondence should be addressed to Yavuz Beyazit, yavuzbeyaz@yahoo.com
}

Received 28 September 2010; Revised 14 October 2010; Accepted 23 October 2010

Academic Editor: Masaki Mogi

Copyright ( 2011 Yavuz Beyazit et al. This is an open access article distributed under the Creative Commons Attribution License, which permits unrestricted use, distribution, and reproduction in any medium, provided the original work is properly cited.

Local hematopoietic bone marrow (BM) renin-angiotensin system (RAS) affects the growth, production, proliferation differentiation, and function of hematopoietic cells. Angiotensin II (Ang II), the dominant effector peptide of the RAS, regulates cellular growth in a wide variety of tissues in pathobiological states. RAS, especially Ang II and Ang II type 1 receptor (AT1R), has considerable proinflammatory and proatherogenic effects on the vessel wall, causing progression of atherosclerosis. Recent investigations, by analyzing several BM chimeric mice whose BM cells were positive or negative for AT1R, disclosed that AT1R in $\mathrm{BM}$ cells participates in the pathogenesis of atherosclerosis. Therefore, AT1R blocking not only in vascular cells but also in the BM could be an important therapeutic approach to prevent atherosclerosis. The aim of this paper is to review the function of local BM RAS in the pathogenesis of atherosclerosis.

\section{Introduction}

The renin-angiotensin system (RAS) plays a crucial role in the control of blood pressure, blood flow, fluid volume, and electrolyte balance, and overactivity of this system contributes to the pathogenesis of a variety of clinical conditions, including onset, progression, and outcome of atherosclerosis [1-3]. Angiotensinogen (AGT) produced in the liver is the precursor of angiotensin I (Ang I), an inactive decapeptide that is converted into Ang II, the main effector of the RAS. Its only role known is as a substrate for renin, a highly specific aspartyl protease. Renin that is secreted from juxtaglomerular apparatus of the kidney cleaves the Nterminal end of AGT to generate Ang I. Ang I is then activated to the Ang II by angiotensin converting enzyme (ACE), which is predominantly expressed in high concentrations on the surface of endothelial cells in the pulmonary circulation [4].

Ang II plays a main role in the RAS mediated mainly by two seven transmembrane domain receptors termed Ang II type 1 receptor (AT1R) and Ang II type 2 receptor (AT2R) showing a complex pattern of regulation and function [5].
Most of the well-known actions of Ang II-AT1R interaction causes vasoconstriction and aldosterone release from the adrenal gland. This classical description of the RAS has been expanded by recent findings that RAS is activated locally, particularly in the vessel wall, heart, the kidney, and the brain [6-14]. Ang II was also described to be produced by other enzymes such as chymase, an efficient Ang II-forming serine protease [15]. It is not affected by ACE inhibition and has been suggested as relevant for alternative pathways of Ang II generation [16-18]. Although several other alternative enzymes involved in Ang II formation such as tonin and cathepsins, chymase deserves special attention due to its high substrate specificity. The enzyme is also expressed in the vascular wall, where it has been suggested as a possible player in Ang II-mediated arteriosclerosis [15].

Inflammatory cells detected in atherosclerotic lesions are mainly originated from bone marrow (BM). The presence of a locally activated bone marrow (BM) RAS affecting the growth, production, proliferation, and differentiation of hematopoietic cells was suggested in 1996 [19]. Other than a wide variety of evidences disclosed the existence of a functional local BM RAS. Angiotensin II, through interacting 
with AT1 receptor enhances erythroid differentiation in the BM [20]. Ang II-stimulated erythroid progenitors formed significantly higher numbers of burst forming unit-erythroid (BFU-E) colonies in normal human erythropoiesis. Recently, Fukuda and Sata [21] proposed a hypothesis that the local RAS in BM plays crucial roles in atherosclerosis. They have demonstrated that Ang II-AT1R pathway in BM contributes to atherosclerotic development in the hypercholesterolemic mice. The aim of this paper is to outline the function of local BM RAS during the course of progression and destabilization of atherosclerosis.

\section{RAS Activation in Atherosclerotic Lesions}

\subsection{Potential Effects of Activated RAS on Vascular Structure.} Atherosclerosis is a chronic inflammatory disease involving accumulation of lipoproteins and mononuclear cells in the subendothelial space with a result of a cascade of events in blood vessels leading to a remodeling of the arterial wall and a consecutive reduction in lumen size. Novel advances in biotechnology and molecular methods have enabled us to understand the molecular pathways that induce and promote inflammatory responses in the formation of atherosclerotic lesions. Although RAS plays a central role in the control of blood pressure, fluid volume, and sodium balance, overactivity of this system contributes to the pathogenesis of atherosclerosis by simulating a series of coordinated cellular and molecular events observed in the lesions [22-25].

In the past Ang II was believed to affect atherosclerosis through its hemodynamic effects, but in the last two decade it has been shown that, direct cellular effects of Ang II affect the structural changes in the vessel wall seen in atherosclerosis [26]. All components of the RAS are expressed in the vessel wall and mostly the effects of Ang II are mediated by the G-protein-coupled receptors AT1 and AT2 [27]. Both AT1R and AT2R have been well identified in the vessel wall; AT1R is believed to mediate most of the atherogenic actions of Ang II [28, 29]. Yang et al. [30] demonstrated that in hypercholesterolemic atherosclerosis in rabbits, the density of AT1 receptors in the media of diseased blood vessels is increased fivefold compared to healthy animals. They also found a significant AT1R binding in the neointima of the diseased arteries. The highest receptor density in the vessel wall is on vascular smooth muscle cells (VSMCs), but cell culture studies also established a significant AT1R-mediated responses in endothelial cells and macrophages and AT2Rs comprise only about $10 \%$ of total angiotensin receptors in healthy blood vessels $[30,31]$. Those results suggested that not only systemic but also local Ang II-AT1R pathway could contribute to initiation and progression of atherosclerosis in blood vessels.

\subsection{Effects of Activated RAS on Vascular Endothelial Cells.} Ang II, produced locally by endothelial ACE, is one of the key substances that affects endothelial function (or dysfunction). To better understand the effect of Ang II on vascular pathobiology, one must need to examine the pivotal role of the endothelium in maintaining normal vascular function and structure. Ang II is synthesized by and has a key action on the endothelium: it exerts direct influence on endothelial function $[7,32]$. Vascular endothelium is known as a metabolically active secretory tissue, presents a thromboresistant surface to blood, and acts as a selective macromolecular barrier. It is now believed that structural abnormalities and function of endothelial cells is the cause of not only vascular diseases including atherosclerosis but also certain visceral disorders [33]. Endothelial cells produce factors that regulate vessel tone, coagulation, cell growth and death, and leukocyte migration. Under the control of the endothelium and other factors, VSMCs are also able to release cytokines and growth-regulatory factors that can influence vascular cellular phenotype and growth $[7,34]$. Cytokines can exert both pro- and antiatherogenic actions because they are multipotent mediators of inflammation and immunity that can affect key functions of vascular wall cells. The functions of vascular wall cells regulated by cytokines may influence lesion initiation, progression, or complication. The cytokines also adjust endothelial functions that control the development and stability of blood thrombi. Thus, cytokines can influence multiple aspects of atherogenesis and provide new and interesting targets for therapeutic management [35]. Endothelial cells also regulate vascular tone in a strict balance between vasodilators-like nitric oxide (NO), and vasoconstrictors-like Ang II. This balance is crucial to a healthy endothelium. When Ang II is elevated, endothelial dysfunction begins. The imbalance toward Ang II by itself can cause many of the changes in the endothelium that set the atherosclerotic process in motion [36].

Ang-II upregulates expression of adhesion molecules, cytokines, and chemokines and exerts a proinflammatory effect on leucocytes, endothelial cells, and VSMCs [22, 24, 26, 37-39]. And also Ang II upregulates expression of vascular endothelial growth factor (VEGF) which contributes to adventitial angiogenesis [40-42]. Acting via the type 1 receptor, Ang II initiates an inflammatory cascade of reduced nicotinamide-adenine dinucleotide phosphate oxidase, reactive oxygen species (ROS), and nuclear factorkappa $\mathrm{B}$, which mediates transcription and gene expression and increases chemokines and adhesion molecules [43]. The Ang II type 1a (AT1a) receptor is expressed on multiple cell types in atherosclerotic lesions, including bonemarrow-derived cells and vascular wall cells, and mediates inflammatory and proliferative responses. Indeed, Ang II infusion accelerates atherogenesis in hyperlipidemic mice by recruiting monocytes and by activating vascular wall cells [44]. In advanced atherosclerotic lesions, Ang II stimulates matrix metalloproteinases (MMPs) and plasminogen activator inhibitor-1 expression, causing destabilization of atherosclerotic plaque and alteration of fibrinolytic balance [45-47].

Besides inducing oxidative stress, endothelial damage, and disease pathology including vasoconstriction, thrombosis, and inflammation, Ang II is also involved in vascular remodeling, acting as a bifunctional growth factor that stimulates production of growth factors and vasoactive agents (e.g., platelet-derived growth factor, insulin-like growth factor, and basic fibroblast growth factor) in VSMCs $[48,49]$. 
Other mechanisms whereby Ang II may promote vascular remodeling and formation of vascular lesions are the modulation of vascular cell migration, decreased vascular smooth muscle apoptosis, and extracellular matrix deposition [5052]. These multiple actions of Ang II are mediated via complex intracellular signaling pathways including stimulation of the PLC-IP3-DAG cascade, tyrosine kinases, MAP kinases, and RhoA/Rho kinase [53]. Intracellular signaling pathways that are stimulated after binding of the peptide to its cell-surface receptors, of which two major subtypes have been characterized, AT1R and AT2R [54, 55]. Although Ang IV receptor was identified recently, as insulin-regulated aminopeptidase, however, its roles in angiogenesis still remain unknown. In humans, AT1R is widely expressed in blood vessels, kidney, heart, liver, and adrenal glands, whereas AT2R is present largely in foetal tissue, decreasing quickly after birth, with relatively low amounts normally expressed in adult tissue [53]. AT1R mediates proangiogenic effect through enhancement of inflammation and leukocytes infiltration, while AT2R mediates antiangiogenic effect through regulation of apoptosis. AT2R expression is increased in pathological circumstances associated with cardiac and vascular remodeling or inflammation. Although they differ in their unique actions, both of the receptors play a crucial role in regulating VSMC function.

2.3. Reactive Oxygen Species and Inflammatory Cells in the Formation of Atherosclerosis. Experimental and clinical studies using Ang II, ACE inhibitors, and AT1 receptor blockers have provided indirect evidence supporting the role of oxidative stress in the pathogenesis of endothelial dysfunction and atherogenesis, independent of the hemodynamic stress of blood pressure [56, 57]. Growing evidence suggests that vascular reactive oxygen species (ROS) play a key role in atherogenesis. Besides its vasoconstrictive properties, Ang II, via the AT1 receptor, generates $\mathrm{O}_{2}$-production in endothelial cells, adventitial fibroblasts, vascular smooth muscle cells (VSMCs), and mesangial cells through activation of nicotinamide adenine dinucleotide (reduced form)/NADH phosphate (reduced form) (NADH/NAD $(\mathrm{P}) \mathrm{H})$ oxidase leading to endothelial dysfunction, growth, and inflammation [58, 59]. Among many ROS generator, nicotinamide dinucleotide phosphate $(\mathrm{NAD}(\mathrm{P}) \mathrm{H})$ oxidase dependent pathway is an important one in vascular system [60]. Recent researches demonstrated that in endothelial cells as well as in VSMCs, $\mathrm{NAD}(\mathrm{P}) \mathrm{H}$-dependent oxidase represents the most significant $\mathrm{O}_{2}$-source. Interestingly, this oxidase is activated upon stimulation with Ang II, suggesting that under all conditions of an activated circulating and/or local RAS endothelial dysfunction secondary to increased vascular $\mathrm{O}_{2}$-production is expected. In a previous study by Barry-Lane et al. [61], it has been demonstrated that $\mathrm{NAD}(\mathrm{P}) \mathrm{H}$ oxidase is a crucial enzyme in the pathogenesis of atherosclerosis by analyzing the genetically altered mice that are lacking for both apolipoprotein $\mathrm{E}$ (ApoE) and p47phox, one subunit of $\mathrm{NAD}(\mathrm{P}) \mathrm{H}$ oxidase. In this interesting study, significant reduction in atherosclerotic lesion was shown in the double knockout mice, compared with that of ApoE-deficient mice.
ROS takes actions not only as a regulator of vascular tonus but also as a second messenger to modify the vascular cell phenotypes. ROS stimulates janus kinase (JAK)/STAT (signal transducers and activators of transcription), Akt, and mitogen-activated protein kinase pathways [62-65]. Increased oxidative stress contributes to endothelial dysfunction and to vascular inflammation by stimulating the redoxsensitive transcription factors (NF-kappa B) and by upregulating adhesion molecules, cytokines, and chemokines.

In the cardiovascular system, the major catalytic subunits of $\mathrm{NAD}(\mathrm{P}) \mathrm{H}$ oxidase are, nox 1, gp91phox (nox 2), and nox 4 , and the regulatory subunits are p22phox, p47phox, p67phox, and rac [59]. The four phox subunits are knownt to be upregulated in endothelial cells and VSMCs from vessels exposed to Ang II [59]. Ang II induces ROS production, one of the most significant mediators of the atherogenic actions of RAS. The ROS produced by Ang II contributes to the pathogenesis of vascular diseases by inactivating nitric oxide, impairing endothelial function, enhancing VSMC growth and proliferation, and stimulating proatherogenic, inflammatory, and adhesion molecule expression [66-68]. Importantly, the Ang II-induced elevation in $\mathrm{O}_{2}$-generation in the vessel wall does not seem to be related to the hemodynamic effects of Ang II, because norepinephrineinduced hypertension did not have a similar effect [57].

Ang II is a key mediator of oxidative stress and decreased activity of NO. Ang II causes the activation of NADH/NADPH oxidase that results in the production of superoxide anion and, subsequently, hydrogen peroxide [69]. Moreover, it has been shown that Ang II plays a cruical role in neointimal monocyte infiltration through NFkappa $\mathrm{B}$ activation and monocyte chemoattractant protein1(MCP-1) expression an important effect that is blocked by angiotensin converting enzyme (ACE) inhibitors [22]. Although Ang II activates NF-kappa B and upregulates expression of cytokines such as interleukin- 6 and tumor necrosis factor- $\alpha$, pharmacological blockade of AT1R with angiotensin receptor blockers would not be so efficient to inhibit cytokine production entirely $[38,70,71]$.

Ang II regulates not only adhesion molecule expressions like vascular cellular adhesion molecule-1 (VCAM1), intercellular adhesion molecule-1 (ICAM-1) and Pselectin but also cytokine, chemokine, and growth factor secretion within the arterial wall [72]. Alternatively, RAS can adjust the activation of complement system in both atherosclerosis and renal injury $[73,74]$. This inflammatory cascade accelerate the vascular inflammatory response by elevating inflammatory cell recruitment to vessel walls. After migrating into the vessel wall, monocytes transform into macrophages and contribute to lipid deposition in the plaque $[75,76]$. Chemokines and MMPs secreted from monocytes/macrophages cause acceleration of atherosclerotic lesions [77]. Furthermore, angiotensin II favors the intraplaque recruitment of monocytes and lymphocytes and directly enhances TNF- $\alpha$, IL- 6 and cyclooxygenase- 2 expression in atherosclerotic arteries [1, 78-80]. Moreover recruited leukocytes themselves have $\mathrm{NAD}(\mathrm{P}) \mathrm{H}$ oxidase subunits and serve as a source of ROS [81]. In addition, Ang II triggered activation of transcription factor nuclear 
factor-kappa B through redox-sensitive pathways, induces cell adhesion molecules as well as the chemokines MCP1 and interleukin-8. These molecules promote monocyte and T-lymphocyte adherence, invasion, and accumulation in atherosclerotic lesions $[22,24,37,82]$. Taken together, these data support a local activated RAS in vessel walls that promotes infiltration of inflammatory cells into the vessel walls, which is an important feature of atherosclerosis.

\section{The Function of Local Bone Marrow RAS}

We have recently reviewed the pathobiological aspects of local hematopoietic BM RAS [83]. The local haematopoietic bone marrow (BM) renin-angiotensin system (RAS) mediates pathobiological alterations of haematopoiesis in an autocrine/paracrine/intracrine fashion [84]. Recent data further indicated the existence of angiotensin-converting enzyme (ACE) in human primitive lympho-haematopoietic cells, embryonic, foetal, and adult haematopoietic tissues $[85,86]$. Human umbilical cord blood cells also express renin, angiotensinogen, and ACE mRNAs [87, 88]. As ACE and other angiotensin peptides function in human haematopoietic stem cells (HSCs) throughout haematopoietic ontogeny and adulthood $[85,86]$, local RAS could also have a function in HSC plasticity, and the development of haematological neoplastic disorders [83, 89, 90]. The presence of ACE on leukaemic blast cells within leukaemic BM [91, 92], on erythroleukaemic cells [93], ACE-expressing macrophages in lymph nodes of Hodgkin disease [94], renin activity in leukaemic blasts [95, 96], Ang II as an autocrine growth factor for AML [97], increased renin gene activity during NUP98-HOXA9-enhanced blast formation [98], higher levels of BB9/ACE (+) AML isoforms [85], and altered JAK-STAT pathway as a link between RAS and leukaemia $[83,99]$ indicated the wide pathobiological aspects of local BM RAS. Local hematopoietic BM RAS particularly mediates pathogenesis of myeloproliferative disorders (MPDs) [83]. JAK-STAT pathway represents the point of crosstalk between the upstream local BM RAS and neoplastic hematopoiesis $[83,99]$. Abnormally enhanced expressions of the main RAS components in MPD are downregulated by the targeted therapy, imatinib mesylate [100]. JAK1 and JAK2 inhibitor, INCB018424, decreased clonal neoplastic cells and downregulated inflammatory responses in MPD [101]. Since neoplasia and inflammation are the main pivotal actions of hematopoietic BM RAS, which is the upstream controlling pathway of JAK-STAT signaling [83, 102]; direct effects of INCB018424 on RAS shall be further searched to understand its clinically translated pleiotropic molecular engagements. The comparable biological actions of local RASs throughout the human body (including myocardium, pancreas, pituitary gland, ovary, and kidney) represent the true basis for the search of their prominence in tissue functions [83].

Interestingly a previous study provided by Savary et al. [103] demonstrated the presence of a locally active RAS in the yolk sac and possible RAS-dependent participation of ACE in the modulation of early yolk sac erythropoiesis. Moreover the discovery that ACE/CD143 marks primitive embryonic hemangioblasts raised the probability that the versatile RAS plays a crucial role in regulating the earliest stages of human hematoendothelial differentiation, as it does in avian embryos. Zambidis et al. [104] successfully demonstrated a dramatic upregulation of AT2R during expansion of human embryoid body (hEB)-derived ACE+ hemangioblasts, which proposes an exclusive role for the RAS in guiding the early developmental phases of human angiohematopoiesis [105-107]. Furthermore they found that hEBderived blast-colony-forming cell could be targeted to differentiate into either hematopoietic or endothelial progeny by manipulating signaling pathways normally mediated by the RAS. And also manipulation of angiotensin II signaling with either AT1R or AT2R specific inhibitors toward either endothelium, or multipotent hematopoietic progenitors, resulted in obvious deviations of hEB differentiation [105].

\section{Local Haematopoietic Bone Marrow RAS in the Pathogenesis of Atherosclerosis}

There is a close interrelationship between hematopoietic bone marrow RAS and the cardiac RAS [105, 106]. Myocardial tissue repair via hematopoietic stem cell plasticity may represent a point of crosstalk between local cardiac RAS and hematopoietic RAS (Figure 1) [89, 108]. Inflammatory mediators particularly macrophages/monocytes, neutrophils and T-lymphocytes play a central role in all phases of atherosclerosis. Atherosclerotic lesions are initiated by endothelial cell damage, followed by monocyte/macrophage adhesion and invasion as well as smooth muscle cell migration and proliferation $[109,110]$. In this perspective, restenosis after angioplasty shares a common pathophysiological process with atherosclerosis, where endothelial injury followed by impaired endothelialization [111, 112]. Previously it has been believed that only migration and proliferation of adjacent endothelial cells in the vessel wall causes reendothelialization, but afterwards it has been proved that endothelial progenitor cells derived from bone marrow (BM) also participate in this course [113-115]. A local RAS in BM has a possible role in endothelial progenitor cell biology causing neovascularization. Recently it has been demonstrated that RAS activation stimulates endothelial progenitor cell proliferation and neovascularization $[26,116]$.

Strawn et al. was the first to propose a lipid-angiotensin system connection within the BM that accounts for the predisposition of immune cells to home to coronary arteries and initiate atherosclerosis [117, 118]. Their data supported a positive regulatory role of plasma LDL on AT1R-mediated haematopoetic stem cell differentiation and the production of proatherogenic monocytes which may explain in part hypercholesterolemia-induced inflammation as well as the anti-inflammatory and antiatherosclerotic effects of AT1R blockers. This innovative theory combines the former lipid hypotheses and allows for an immunological activation concept that begins as early as changes in the $\mathrm{BM}$ that result in the generation of activated circulating monocytic phenotypes that participate in atherogenesis. The "bone marrow response-to-lipid" hypothesis incorporates 

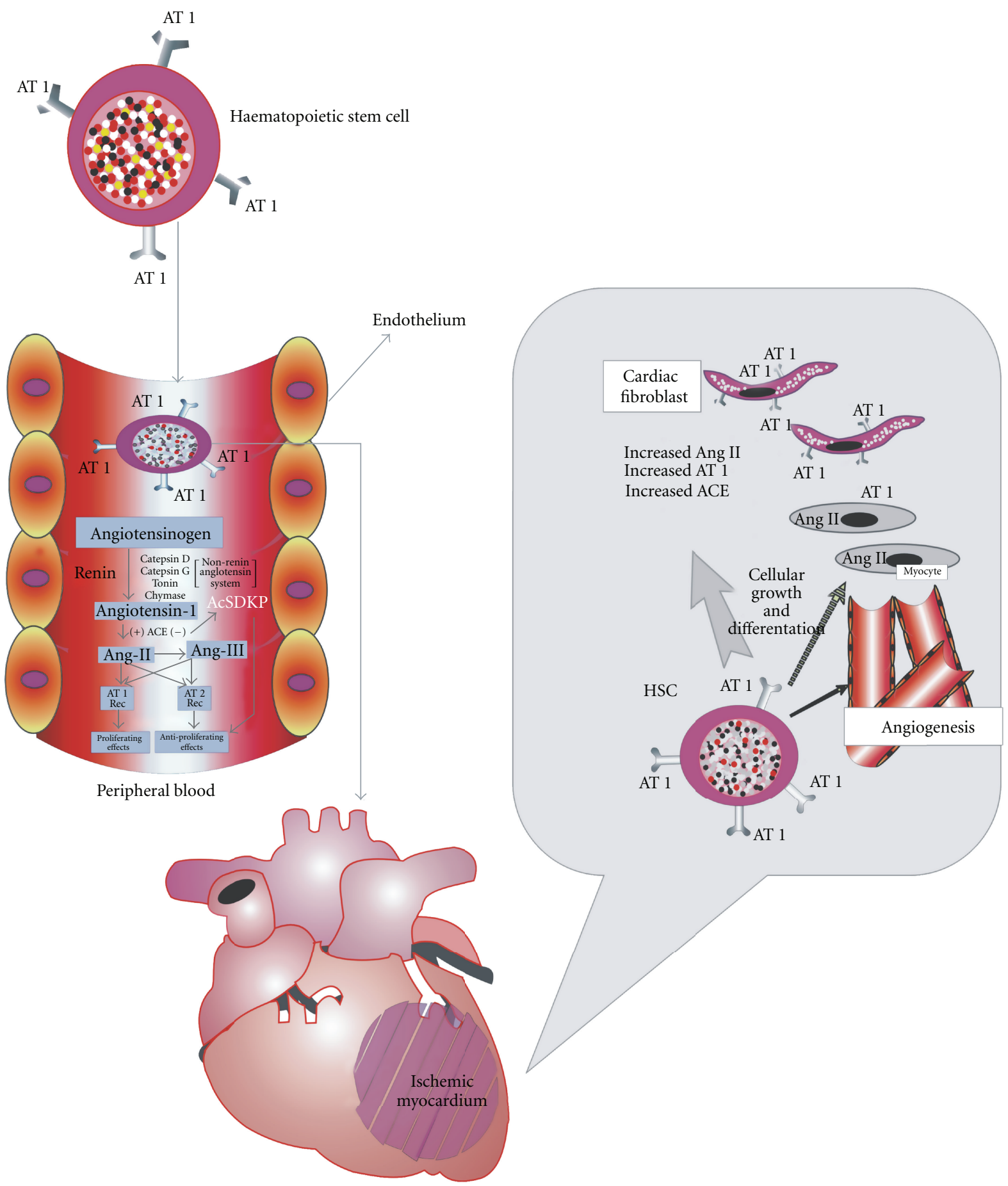

FIGURE 1: Possible functions of hematopoietic stem cells in the vasculature and cardiac microenvironment, suggesting the interrelationships of local bone marrow renin-angiotensin system (RAS), circulating RAS, and local myocardial RAS.

the idea that proatherogenic properties of hematopoietic and nonhematopoietic progenitors are determined by the local actions of modified LDL on the expression of local RAS genes [117].

Fukuda and Sata successfully demonstrated that BMderived cells significantly contribute to the development of atherosclerotic lesions [21, 26, 119]. Although Ang
II is supposed to promote contribution of BM-derived cells to atherosclerosis by enhancing their mobilization, recruitment, differentiation, and proliferation, Fukuda and Sata performed an experiment for to evaluate the potential participation of $\mathrm{ATlaR}$ in $\mathrm{BM}$ in the pathogenesis of atherosclerosis. They generated several combinations of BM chimeric mice in a murine model of hyperlipidemia and 
atherosclerosis by analyzing several BM chimeric mice whose $\mathrm{BM}$ cells were positive or negative for ATlaR. They also mentioned that Ang II infusion increased the number of smooth muscle progenitor cells, which are peripheral blood cells that turn to $\alpha$-smooth muscle actin-positive cells after culture in the presence of PDGF-BB. These smooth musclelike cells expressed abundant matrix metalloproteinase-9 (MMP-9), which substantially contribute to destabilization of atherosclerotic plaques [21]. Their results suggested that blockade of AT1R not only in vascular cells but also in BM could be an important strategy to prevent atherosclerosis. In a previous study by Cassis et al. [120] it has been shown that, bone marrow recipient ATla receptors are required to initiate Ang II-induced atherosclerosis in hypercholesterolemic mice in which bone marrow transplantation studies were performed. They have concluded that AT1a receptors expressed on infiltrating cells exert modest regulation of Ang II-induced atherosclerosis. Moreover the existence of this receptor in resident tissue is necessary for the initiation of Ang II-induced atherosclerosis and abdominal aortic aneurysms. An other study by Tsubakimoto et al. [121], the Ang II regulated differentiation/proliferation of monocyte-lineage cells to exert proatherogenic actions was clearly defined. In this study the authors generated $\mathrm{BM}$ chimeric apoE negative mice repopulated with AT1deficient $\left(\right.$ Agtr1 $\left.1^{-/-}\right)$or wild-type $\left(\operatorname{Agtr} 1^{+/+}\right)$) BM cells. The atherosclerotic development was significantly reduced in

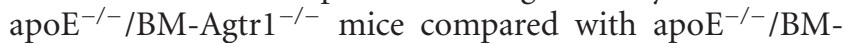
Agtr $1^{+/+}$mice, accompanied by decreased numbers of BM granulocyte/macrophage progenitors and peripheral blood monocytes. And finally they have been proposed that Ang II controls the expression of c-Fms in HSCs and monocytelineage cells through BM stromal cell derived TNF-alpha to promote $\mathrm{M}$-CSF-induced differentiation/proliferation of monocyte-lineage cells and contributes to the proatherogenic action [121].

In contrary to the studies demonstrating that $[21,122]$ blockade of AT1 receptor in BM cells might have inhibitory effects on atherosclerosis, little or no changes of atherosclerosis in LDL receptor knockout mice by transplantation with BM from AT1a receptor knockout mice are also reported $[120,123]$. These reports suggest the ameliorative function of AT1 receptor blockade in vascular cells for the AT1 receptor blocker- (ARB-) mediated atherosclerosis inhibition. In conjunction with the latter reports, the study by Kato et al. [124] also demonstrates that the beneficial effects of ARB in end-organ injuries are due to the blockade of AT1 receptor expressed in the end organs, but not in bone-marrow-derived cells. They proposed that distinct results observed in the kidney injury and atherosclerosis is possibly from the differences in the pathogenesis of mouse models. Moreover they have speculated that depending upon the tissues and model systems examined, AT1 receptor function in BMDCs may have differential action points.

Taken as a whole, the hematopoietic BM RAS, as well as local vasculature RAS, plays a crucial role in the initiation and progression of atherosclerosis, thereby contributing to development of cardiovascular diseases.

\section{Future Therapeutic Perspectives}

Endothelial dysfunction, cellular proliferation, and programmed inflammation triggered by RAS provide a clue to a novel understanding of the pathological hallmark of atherosclerosis, and may be important in developing new antiatherosclerotic strategies. ATlaR expressed on BMderived cells plays a crucial role in the pathogenesis of atherosclerosis by accelerating BM-derived inflammatory cell infiltration in the vessel wall. For that reason, AT1R blockade not only in vascular cells but also in BM could help to prevent progression and destabilization of atherosclerotic plaques [21, 26, 117, 119, 125]. Pharmacological therapeutic strategies must focus on the distribution and the density of angiotensin receptors, gene expression, and proteomics along hematopoietic BM structures. Future therapeutic interventions would interfere with the pathobiological activation of the local hematopoietic BM in a variety of diseases, particularly atherosclerosis, to elucidate the importance of the system from an actual clinical point of view.

In summary, a large number of studies have shown that RAS has a central role in the initiation and progression of atherosclerosis, as outlined in this paper. Ang II may compromise the structural integrality of the endothelial barrier by induction of endothelial cell apoptosis. Inflammatory reaction in the vascular intimal layer involving macrophages and $\mathrm{T}$ lymphocytes by RAS-induced oxidative stress and hyperthrombotic state results in oxidative lipoprotein modification, smooth muscle cell migration from the media into the intima, proliferation, and transformation from a contractile to a synthetic phenotype. While the earlier stages may remain subclinical, this stage of the atherosclerotic process leads to a significant reduction in the vessel lumen. ATlaR expressed not only on vascular cells but also on $\mathrm{BM}$-derived cells plays a role in the atherosclerotic plaque pathogenesis, at least partially by accelerating infiltration of BM-derived inflammatory cells in the vessel wall. Understanding the diversity of intracellular Ang II synthesis pathways may help in developing therapeutic interventions, and blockade of AT1R not only in vascular cells but also in BM could be an important strategy to prevent progression and destabilization of atherosclerotic plaques.

\section{Acknowledgment}

The authors would like to thank to Dr. Sureyya Altunay, for providing them an excellent illustration of local hematopoietic bone marrow RAS in association with cardiac RAS.

\section{References}

[1] C. M. Ferrario and W. B. Strawn, "Role of the reninangiotensin-aldosterone system and proinflammatory mediators in cardiovascular disease," American Journal of Cardiology, vol. 98, no. 1, pp. 121-128, 2006.

[2] S. Oparil and E. Haber, "The renin-angiotensin system (first of two parts)," New England Journal of Medicine, vol. 291, no. 9, pp. 389-401, 1974. 
[3] S. Oparil and E. Haber, "The renin angiotensin system (Second of two parts)," New England Journal of Medicine, vol. 291, no. 9, pp. 446-457, 1974.

[4] M. Paul, A. P. Mehr, and R. Kreutz, "Physiology of local renin-angiotensin systems," Physiological Reviews, vol. 86, no. 3, pp. 747-803, 2006.

[5] M. de Gasparo, K. J. Catt, T. Inagami, J. W. Wright, and TH. Unger, "International union of pharmacology. XXIII. The angiotensin II receptors," Pharmacological Reviews, vol. 52, no. 3, pp. 415-472, 2000.

[6] V. J. Dzau, "Tissue angiotensin and pathobiology of vascular disease a unifying hypothesis," Hypertension, vol. 37 , no. 4, pp. 1047-1052, 2001.

[7] M. Ruiz-Ortega, O. Lorenzo, M. Rupérez et al., "Role of the renin-angiotensin system in vascular diseases: expanding the field," Hypertension, vol. 38, no. 6, pp. 1382-1387, 2001.

[8] V. J. Dzau and R. Re, "Tissue angiotensin system in cardiovascular medicine: a paradigm shift?" Circulation, vol. 89, no. 1, pp. 493-498, 1994.

[9] J. N. Cohn and G. Tognoni, "A randomized trial of the angiotensin-receptor blocker valsartan in chronic heart failure," New England Journal of Medicine, vol. 345, no. 23, pp. 1667-1675, 2001.

[10] R. A. Lafayette, G. Mayer, S. K. Park, and T. W. Meyer, "Angiotensin II receptor blockade limits glomerular injury in rats with reduced renal mass," Journal of Clinical Investigation, vol. 90, no. 3, pp. 766-771, 1992.

[11] H. Yamagishi, S. Kim, T. Nishikimi, K. Takeuchi, and T. Takeda, "Contribution of cardiac renin-angiotensin system to ventricular remodelling in myocardial-infarcted rats," Journal of Molecular and Cellular Cardiology, vol. 25, no. 11, pp. 1369-1380, 1993.

[12] H. F. Cheng, B. N. Becker, K. D. Burns, and R. C. Harris, "Angiotensin II upregulates type-1 angiotensin II receptors in renal proximal tubule," Journal of Clinical Investigation, vol. 95, no. 5, pp. 2012-2019, 1995.

[13] R. H. Yang, H. Jin, J. M. Wyss, and S. Oparil, "Depressor effect of blocking angiotensin subtype 1 receptors in anterior hypothalamus," Hypertension, vol. 19, no. 5, pp. 475-481, 1992.

[14] M. I. Phillips and C. Sumners, "Angiotensin II in central nervous system physiology," Regulatory Peptides, vol. 78, no. 1-3, pp. 1-11, 1998.

[15] K. Arakawa and H. Urata, "Hypothesis regarding the pathophysiological role of alternative pathways of angiotensin II formation in atherosclerosis," Hypertension, vol. 36, no. 4, pp. 638-641, 2000.

[16] H. Urata, H. Nishimura, and D. Ganten, "Chymasedependent angiotensin II forming system in humans," American Journal of Hypertension, vol. 9, no. 3, pp. 277-284, 1996.

[17] H. Urata, A. Kinoshita, D. M. Perez et al., "Cloning of the gene and cDNA for human heart chymase," Journal of Biological Chemistry, vol. 266, no. 26, pp. 17173-17179, 1991.

[18] A. Wolny, J. P. Clozel, J. Rein et al., "Functional and biochemical analysis of angiotensin II-forming pathways in the human heart," Circulation Research, vol. 80, no. 2, pp. 219-227, 1997.

[19] I. C. Haznedaroglu, S. Tuncer, and M. Gursoy, "A local reninangiotensin system in the bone marrow," Medical Hypotheses, vol. 46 , no. 6, pp. 507-510, 1996 .

[20] H. Kato, J. Ishida, S. Imagawa et al., "Enhanced erythropoiesis mediated by activation of the renin-angiotensin system via angiotensin II type 1a receptor," FASEB Journal, vol. 19, no. 14, pp. 2023-2025, 2005.
[21] D. Fukuda and M. Sata, "Role of bone marrow reninangiotensin system in the pathogenesis of atherosclerosis," Pharmacology and Therapeutics, vol. 118, no. 2, pp. 268-276, 2008.

[22] M. Hernández-Presa, C. Bustos, M. Ortego et al., "Angiotensin-converting enzyme inhibition prevents arterial nuclear factor- $\kappa \mathrm{B}$ activation, monocyte chemoattractant protein-1 expression, and macrophage infiltration in a rabbit model of early accelerated atherosclerosis," Circulation, vol. 95, no. 6, pp. 1532-1541, 1997.

[23] L. Pastore, A. Tessitore, S. Martinotti et al., "Angiotensin II stimulates intercellular adhesion molecule-1 (ICAM-1) expression by human vascular endothelial cells and increases soluble ICAM-1 release in vivo," Circulation, vol. 100, no. 15, pp. 1646-1652, 1999.

[24] M. E. Pueyo, W. Gonzalez, A. Nicoletti, F. Savoie, J. F. Arnal, and J. B. Michel, "Angiotensin II stimulates endothelial vascular cell adhesion molecule-1 via nuclear factor- $\kappa \mathrm{B}$ activation induced by intracellular oxidative stress," Arteriosclerosis, Thrombosis, and Vascular Biology, vol. 20, no. 3, pp. 645-651, 2000.

[25] T. Petnehazy, K. Y. Stokes, K. C. Wood, J. Russell, and D. N. Granger, "Role of blood cell-associated AT1 receptors in the microvascular responses to hypercholesterolemia," Arteriosclerosis, Thrombosis, and Vascular Biology, vol. 26, no. 2, pp. 313-318, 2006.

[26] M. Sata and D. Fukuda, "Crucial role of renin-angiotensin system in the pathogenesis of atherosclerosis," Journal of Medical Investigation, vol. 57, no. 1-2, pp. 12-25, 2010.

[27] N. Iwai and T. Inagami, "Identification of two subtypes in the rat type I angiotensin II receptor," FEBS Letters, vol. 298, no. 2-3, pp. 257-260, 1992.

[28] S. Nouet and C. Nahmias, "Signal transduction from the angiotensin II AT receptor," Trends in Endocrinology and Metabolism, vol. 11, no. 1, pp. 1-6, 2000.

[29] P. P. Sayeski and K. E. Bernstein, "Signal transduction mechanisms of the angiotensin II type AT-receptor: looking beyond the heterotrimeric G protein paradigm," Journal of the Renin-Angiotensin-Aldosterone System, vol. 2, no. 1, pp. 4-10, 2001.

[30] B. C. Yang, M. I. Phillips, D. Mohuczy et al., "Increased angiotensin II type 1 receptor expression in hypercholesterolemic atherosclerosis in rabbits," Arteriosclerosis, Thrombosis, and Vascular Biology, vol. 18, no. 9, pp. 1433-1439, 1998.

[31] Z. Q. Wang, A. F. Moore, R. Ozono, H. M. Siragy, and R. M. Carey, "Immunolocalization of subtype 2 angiotensin II (AT) receptor protein in rat heart," Hypertension, vol. 32, no. 1, pp. 78-83, 1998.

[32] G. H. Gibbons and V. J. Dzau, "The emerging concept of vascular remodeling," New England Journal of Medicine, vol. 330, no. 20, pp. 1431-1438, 1994.

[33] K. A. Robinson, F. J. Candal, N. A. Scott, and E. W. Ades, "Seeding of vascular grafts with an immortalized human dermal microvascular endothelial cell line," Angiology, vol. 46, no. 2, pp. 107-114, 1995.

[34] S. Kinlay and P. Ganz, "Role of endothelial dysfunction in coronary artery disease and implications for therapy," American Journal of Cardiology, vol. 80, no. 9, pp. 11I-16I, 1997.

[35] P. Libby, G. Sukhova, R. T. Lee, and Z. S. Galis, "Cytokines regulate vascular functions related to stability of the atherosclerotic plaque," Journal of Cardiovascular Pharmacology, vol. 25, supplement 2, pp. S9-S12, 1995. 
[36] J. M. Neutel, "Effect of the renin-angiotensin system on the vessel wall: using ACE inhibition to improve endothelial function," Journal of Human Hypertension, vol. 18, no. 9, pp. 599-606, 2004.

[37] L. Gu, Y. Okada, S. K. Clinton et al., "Absence of monocyte chemoattractant protein-1 reduces atherosclerosis in low density lipoprotein receptor-deficient mice," Molecular Cell, vol. 2, no. 2, pp. 275-281, 1998.

[38] Y. Han, M. S. Runge, and A. R. Brasier, "Angiotensin II induces interleukin-6 transcription in vascular smooth muscle cells through pleiotropic activation of nuclear factor$\kappa \mathrm{b}$ transcription factors," Circulation Research, vol. 84, no. 6, pp. 695-703, 1999.

[39] A. R. Brasier, A. Recinos, M. S. Eledrisi, and M. S. Runge, "Vascular inflammation and the renin-angiotensin system," Arteriosclerosis, Thrombosis, and Vascular Biology, vol. 22, no. 8, pp. 1257-1266, 2002.

[40] B. Williams, A. Q. Baker, B. Gallacher, and D. Lodwick, "Angiotensin II increases vascular permeability factor gene expression by human vascular smooth muscle cells," Hypertension, vol. 25, no. 5, pp. 913-917, 1995.

[41] C. Cheng, D. Tempel, R. Van Haperen et al., "Atherosclerotic lesion size and vulnerability are determined by patterns of fluid shear stress," Circulation, vol. 113, no. 23, pp. 27442753, 2006.

[42] P. R. Moreno, K. R. Purushothaman, M. Sirol, A. P. Levy, and V. Fuster, "Neovascularization in human atherosclerosis," Circulation, vol. 113, no. 18, pp. 2245-2252, 2006.

[43] P. Dandona, S. Dhindsa, H. Ghanim, and A. Chaudhuri, "Angiotensin II and inflammation: the effect of angiotensinconverting enzyme inhibition and angiotensin II receptor blockade," Journal of Human Hypertension, vol. 21, no. 1, pp. 20-27, 2007.

[44] J. I. Koga, K. Egashira, T. Matoba et al., "Essential role of angiotensin II type la receptors in the host vascular wall, but not the bone marrow, in the pathogenesis of angiotensin IIinduced atherosclerosis," Hypertension Research, vol. 31, no. 9, pp. 1791-1800, 2008.

[45] Z. S. Galis and J. J. Khatri, "Matrix metalloproteinases in vascular remodeling and atherogenesis: the good, the bad, and the ugly," Circulation Research, vol. 90, no. 3, pp. 251262, 2002.

[46] J. Chen, D. Li, R. F. Schaefer, and J. L. Mehta, "Inhibitory effect of candesartan and rosuvastatin on CD40 and MMPs expression in Apo-E knockout mice: novel insights into the role of RAS and dyslipidemia in atherogenesis," Journal of Cardiovascular Pharmacology, vol. 44, no. 4, pp. 446-452, 2004.

[47] M. Luchtefeld, K. Grote, C. Grothusen et al., "Angiotensin II induces MMP-2 in a p47phox-dependent manner," Biochemical and Biophysical Research Communications, vol. 328, no. 1, pp. 183-188, 2005.

[48] H. Itoh, M. Mukoyama, R. E. Pratt, G. H. Gibbons, and V. J. Dzau, "Multiple autocrine growth factors modulate vascular smooth muscle cell growth response to angiotensin II," Journal of Clinical Investigation, vol. 91, no. 5, pp. 2268 2274, 1993.

[49] A. J. Naftilan, R. E. Pratt, and V. J. Dzau, "Induction of platelet-derived growth factor A-chain and c-myc gene expressions by angiotensin II in cultured rat vascular smooth muscle cells," Journal of Clinical Investigation, vol. 83, no. 4, pp. 1419-1424, 1989.

[50] M. J. Pollman, T. Yamada, M. Horiuchi, and G. H. Gibbons, "Vasoactive substances regulate vascular smooth muscle cell apoptosis: countervailing influences of nitric oxide and angiotensin II," Circulation Research, vol. 79, no. 4, pp. 748756, 1996.

[51] T. Takagishi, N. Murahashi, S. Azagami, M. Morimatsu, and Y. Sasaguri, "Effect of angiotensin II and thromboxane A2 on the production of matrix metalloproteinase by human aortic smooth muscle cells," Biochemistry and Molecular Biology International, vol. 35, no. 2, pp. 265-273, 1995.

[52] T. Scott-Burden, A. W. A. Hahn, T. J. Resink, and F. R. Buhler, "Modulation of extracellular matrix by angiotensin II: stimulated glycoconjugate synthesis and growth in vascular smooth muscle cells," Journal of Cardiovascular Pharmacology, vol. 16, supplement 4, pp. S36-S41, 1990.

[53] R. M. Touyz, "Intracellular mechanisms involved in vascular remodelling of resistance arteries in hypertension: role of angiotensin II," Experimental Physiology, vol. 90, no. 4, pp. 449-455, 2005.

[54] R. M. Touyz and E. L. Schiffrin, "Signal transduction mechanisms mediating the physiological and pathophysiological actions of angiotensin II in vascular smooth muscle cells," Pharmacological Reviews, vol. 52, no. 4, pp. 639-672, 2000.

[55] T. J. Murphy, R. W. Alexander, K. K. Griendling, M. S. Runge, and K. E. Bernstein, "Isolation of a cDNA encoding the vascular type-1 angiotensin II receptor," Nature, vol. 351, no. 6323, pp. 233-236, 1991.

[56] I. H. Schulman, M. S. Zhou, and L. Raij, "Nitric oxide, angiotensin II, and reactive oxygen species in hypertension and atherogenesis," Current Hypertension Reports, vol. 7, no. 1, pp. 61-67, 2005.

[57] J. B. Laursen, S. Rajagopalan, Z. Galis, M. Tarpey, B. A. Freeman, and D. G. Harrison, "Role of superoxide in angiotensin II-induced but not catecholamine- induced hypertension," Circulation, vol. 95, no. 3, pp. 588-593, 1997.

[58] K. K. Griendling and G. A. FitzGerald, "Oxidative stress and cardiovascular injury: part I: basic mechanisms and in vivo monitoring of ROS," Circulation, vol. 108, no. 16, pp. 1912 1916, 2003.

[59] B. Lassègue and R. E. Clempus, "Vascular NAD(P)H oxidases: specific features, expression, and regulation," American Journal of Physiology, vol. 285, no. 2, pp. R277-R297, 2003.

[60] K. K. Griendling, D. Sorescu, and M. Ushio-Fukai, "NAD $(\mathrm{P}) \mathrm{H}$ oxidase: role in cardiovascular biology and disease," Circulation Research, vol. 86, no. 5, pp. 494-501, 2000.

[61] P. A. Barry-Lane, C. Patterson, M. Van Der Merwe et al., "p47phox is required for atherosclerotic lesion progression in ApoE mice (-/-)," Journal of Clinical Investigation, vol. 108, no. 10, pp. 1513-1522, 2001.

[62] C. Viedt, U. Soto, H. I. Krieger-Brauer et al., "Differential activation of mitogen-activated protein kinases in smooth muscle cells by angiotensin II: involvement of p22phox and reactive oxygen species," Arteriosclerosis, Thrombosis, and Vascular Biology, vol. 20, no. 4, pp. 940-948, 2000.

[63] M. Ushio-Fukai, R. W. Alexander, M. Akers et al., "Reactive oxygen species mediate the activation of Akt/protein kinase B by angiotensin II in vascular smooth muscle cells," Journal of Biological Chemistry, vol. 274, no. 32, pp. 22699-22704, 1999.

[64] B. Schieffer, M. Luchtefeld, S. Braun, A. Hilfiker, D. HilfikerKleiner, and H. Drexler, "Role of $\mathrm{NAD}(\mathrm{P}) \mathrm{H}$ oxidase in angiotensin II-induced JAK/STAT signaling and cytokine induction," Circulation Research, vol. 87, no. 12, pp. 11951201, 2000.

[65] A. R. Simon, U. Rai, B. L. Fanburg, and B. H. Cochran, "Activation of the JAK-STAT pathway by reactive oxygen 
species," American Journal of Physiology, vol. 275, no. 6, part 1, pp. C1640-C1652, 1998.

[66] A. Warnholtz, G. Nickenig, E. Schulz et al., "Increased $\mathrm{NADH}$-oxidase-mediated superoxide production. In the early stages of atherosclerosis evidence for involvement of the renin-angiotensin system," Circulation, vol. 99, no. 15, pp. 2027-2033, 1999.

[67] G. Desideri, M. C. Bravi, M. Tucci et al., "Angiotensin II inhibits endothelial cell motility through an AT-dependent oxidant-sensitive decrement of nitric oxide availability," Arteriosclerosis, Thrombosis, and Vascular Biology, vol. 23, no. 7, pp. 1218-1223, 2003.

[68] M. K. Cathcart, "Regulation of superoxide anion production by NADPH oxidase in monocytes/macrophages: contributions to atherosclerosis," Arteriosclerosis, Thrombosis, and Vascular Biology, vol. 24, no. 1, pp. 23-28, 2004.

[69] K. K. Griendling, C. A. Minieri, J. D. Ollerenshaw, and R. W. Alexander, "Angiotensin II stimulates NADH and NADPH oxidase activity in cultured vascular smooth muscle cells," Circulation Research, vol. 74, no. 6, pp. 1141-1148, 1994.

[70] A. W. A. Hahn, "Activation of human peripheral monocytes by angiotensin II," FEBS Letters, vol. 347, no. 2-3, pp. 178180, 1994.

[71] A. R. Brasier, M. Jamaluddin, Y. Han, C. Patterson, and M. S. Runge, "Angiotensin II induces gene transcription through cell-type-dependent effects on the nuclear factor- $\kappa \mathrm{B}$ (NF- $\kappa \mathrm{B})$ transcription factor," Molecular and Cellular Biochemistry, vol. 212, no. 1-2, pp. 155-169, 2000.

[72] M. Graninger, R. Reiter, C. Drucker, E. Minar, and B. Jilma, "Angiotensin receptor blockade decreases markers of vascular inflammation," Journal of Cardiovascular Pharmacology, vol. 44, no. 3, pp. 335-339, 2004.

[73] E. Shagdarsuren, M. Wellner, J. H. Braesen et al., "Complement activation in angiotensin II-induced organ damage," Circulation Research, vol. 97, no. 7, pp. 716-724, 2005.

[74] M. Epstein, "Aldosterone and the hypertensive kidney: its emerging role as a mediator of progressive renal dysfunction: a paradigm shift," Journal of Hypertension, vol. 19, no. 5, pp. 829-842, 2001.

[75] T. Hayek, J. Attias, R. Coleman et al., "The angiotensinconverting enzyme inhibitor, fosinopril, and the angiotensin II receptor antagonist, losartan, inhibit LDL oxidation and attenuate atherosclerosis independent of lowering blood pressure in apolipoprotein E deficient mice," Cardiovascular Research, vol. 44, no. 3, pp. 579-587, 1999.

[76] S. Keidar, R. Heinrich, M. Kaplan, T. Hayek, and M. Aviram, "Angiotensin II administration to atherosclerotic mice increases macrophage uptake of oxidized LDL: a possible role for interleukin-6," Arteriosclerosis, Thrombosis, and Vascular Biology, vol. 21, no. 9, pp. 1464-1469, 2001.

[77] O. Soehnlein, S. Eskafi, A. Schmeisser, H. Kloos, W. G. Daniel, and C. D. Garlichs, "Atorvastatin induces tissue transglutaminase in human endothelial cells," Biochemical and Biophysical Research Communications, vol. 322, no. 1, pp. 105-109, 2004.

[78] F. Montecucco, A. Pende, and F. MacH, "The reninangiotensin system modulates inflammatory processes in atherosclerosis: evidence from basic research and clinical studies," Mediators of Inflammation, vol. 2009, Article ID 752406, 2009.

[79] U. N. Das, "Is angiotensin-II an endogenous proinflammatory molecule?" Medical Science Monitor, vol. 11, no. 5, pp. RA155-RA162, 2005.
[80] V. Fuster and J. Sanz, "Vascular inflammation," Journal of the American Society of Hypertension, vol. 1, no. 1, pp. 68-81, 2007.

[81] A. E. Vendrov, Z. S. Hakim, N. R. Madamanchi, M. Rojas, C. Madamanchi, and M. S. Runge, "Atherosclerosis is attenuated by limiting superoxide generation in both macrophages and vessel wall cells," Arteriosclerosis, Thrombosis, and Vascular Biology, vol. 27, no. 12, pp. 2714-2721, 2007.

[82] P. E. Tummala, XI. L. Chen, C. L. Sundell et al., "Angiotensin II induces vascular cell adhesion molecule-1 expression in rat vasculature: a potential link between the renin-angiotensin system and atherosclerosis," Circulation, vol. 100, no. 11, pp. 1223-1229, 1999.

[83] I. C. Haznedaroglu and Y. Beyazit, "Pathobiological aspects of the local bone marrow renin-;angiotensin system: a review," Journal of the Renin-Angiotensin-Aldosterone System, vol. 11, no. 4, pp. 205-213, 2010.

[84] I. C. Haznedaroglu and M. A. Öztürk, "Towards the understanding of the local hematopoietic bone marrow reninangiotensin system," International Journal of Biochemistry and Cell Biology, vol. 35, no. 6, pp. 867-880, 2003.

[85] V. J. Jokubaitis, L. Sinka, R. Driessen et al., "Angiotensinconverting enzyme (CD143) marks hematopoietic stem cells in human embryonic, fetal, and adult hematopoietic tissues," Blood, vol. 111, no. 8, pp. 4055-4063, 2008.

[86] E. T. Zambidis, T. S. Park, W. Yu et al., "Expression of angiotensin-converting enzyme (CD143) identifies and regulates primitive hemangioblasts derived from human pluripotent stem cells," Blood, vol. 112, no. 9, pp. 3601-3614, 2008.

[87] H. Goker, I. C. Haznedaroglu, Y. Beyazit et al., "Local umbilical cord blood renin-angiotensin system," Annals of Hematology, vol. 84, no. 5, pp. 277-281, 2005.

[88] K. Acar, Y. Beyazit, A. Sucak et al., "Alterations in the 'local umbilical cord blood renin-angiotensin system' during preeclampsia," Acta Obstetricia et Gynecologica Scandinavica, vol. 86, no. 10, pp. 1193-1199, 2007.

[89] M. A. Öztürk, G. S. Güven, and I. C. Haznedaroglu, "How hematopoietic stem cells know and act in cardiac microenvironment for stem cell plasticity? Impact of local renin-angiotensin systems," Medical Hypotheses, vol. 63, no. 5, pp. 866-874, 2004.

[90] S. Aksu, Y. Beyazit, I. C. Haznedaroglu et al., "Enhanced expression of the local haematopoietic bone marrow reninangiotensin system in polycythemia rubra vera," Journal of International Medical Research, vol. 33, no. 6, pp. 661-667, 2005.

[91] S. Aksu, Y. Beyazit, I. C. Haznedaroglu et al., "Overexpression of angiotensin-converting enzyme (CD 143) on leukemic blasts as a clue for the activated local bone marrow RAS in AML," Leukemia and Lymphoma, vol. 47, no. 5, pp. 891-896, 2006.

[92] Y. Beyazit, S. Aksu, I. C. Haznedaroglu et al., "Overexpression of the local bone marrow renin-angiotensin system in acute myeloid leukemia," Journal of the National Medical Association, vol. 99, no. 1, pp. 57-63, 2007.

[93] E. Koca, I. C. Haznedaroglu, K. Acar et al., "Reninangiotensin system expression in the K562 human erythroleukaemic cell line," Journal of the Renin-AngiotensinAldosterone System, vol. 8, no. 3, pp. 145-147, 2007.

[94] E. Koca, I. C. Haznedaroglu, A. Uner et al., "Angiotensinconverting enzyme expression of the lymphoma-associated macrophages in the lymph nodes of Hodgkin's disease," 
Journal of the National Medical Association, vol. 99, no. 11, pp. 1243-1247, 2007.

[95] G. G. Wulf, G. Jahns-Streusel, R. Nobiling et al., "Renin in acute myeloid leukaemia blasts," British Journal of Haematology, vol. 100, no. 2, pp. 335-337, 1998.

[96] G. G. Wulf, G. Jahns-Streubel, F. Strutz et al., "Paraneoplastic hypokalemia in acute myeloid leukemia: a case of renin activity in AML blast cells," Annals of Hematology, vol. 73, no. 3, pp. 139-141, 1996.

[97] R. P. Pinto, K. K. Wang, H. Khoury, A. D. Schimmer, and M. D. Minden, "Aberrant expression of angiotensin in acute myeloid leukemia," Blood, vol. 102, p. 2124A, 2004.

[98] A. Takeda, C. Goolsby, and N. R. Yaseen, "NUP98-HOXA9 induces long-term proliferation and blocks differentiation of primary human CD34 hematopoietic cells," Cancer Research, vol. 66, no. 13, pp. 6628-6637, 2006.

[99] I. C. Haznedaro, M. Arici, and Y. Büyükaşik, "A unifying hypothesis for the renin-angiotensin system and hematopoiesis: sticking the pieces together with the JAKSTAT pathway," Medical Hypotheses, vol. 54, no. 1, pp. 80-83, 2000.

[100] M. Sayitoglu, I. C. Haznedaroǧlu, O. Hatirnaz et al., "Effects of imatinib mesylate on Renin-Angiotensin System (RAS) activity during the clinical course of chronic myeloid leukaemia," Journal of International Medical Research, vol. 37, no. 4, pp. 1018-1028, 2009.

[101] S. Verstovsek, H. Kantarjian, R. A. Mesa et al., "Safety and efficacy of INCB018424, a JAK1 and JAK2 inhibitor, in myelofibrosis," New England Journal of Medicine, vol. 363, no. 12, pp. 1117-1127, 2010.

[102] M. M. Vrsalovic, V. Pejsa, T. S. Veic et al., "Bone marrow renin-angiotensin system expression in polycythemia vera and essential thrombocythemia depends on JAK2 mutational status," Cancer Biology and Therapy, vol. 6, no. 9, pp. 14341436, 2007.

[103] K. Savary, A. Michaud, J. Favier, E. Larger, P. Corvol, and J. M. Gasc, "Role of the renin-angiotensin system in primitive erythropoiesis in the chick embryo," Blood, vol. 105, no. 1, pp. 103-110, 2005.

[104] E. T. Zambidis, B. Peault, T. S. Park, F. Bunz, and C. I. Civin, "Hematopoietic differentiation of human embryonic stem cells progresses through sequential hematoendothelial, primitive, and definitive stages resembling human yolk sac development," Blood, vol. 106, no. 3, pp. 860-870, 2005.

[105] A. Peters, P. W. Burridge, M. V. Pryzhkova et al., "Challenges and strategies for generating therapeutic patient-specific hemangioblasts and hematopoietic stem cells from human pluripotent stem cells," International Journal of Developmental Biology, vol. 54, no. 6-7, pp. 965-990, 2010.

[106] C. Hubert, K. Savary, J. M. Gasc, and P. Corvol, "The hematopoietic system: a new niche for the renin-angiotensin system," Nature Clinical Practice Cardiovascular Medicine, vol. 3, no. 2, pp. 80-85, 2006.

[107] S. C. Heffelfinger, "The renin angiotensin system in the regulation of angiogenesis," Current Pharmaceutical Design, vol. 13, no. 12, pp. 1215-1229, 2007.

[108] F. P. Limbourg and H. Drexler, "Bone marrow stem cells for myocardial infarction: effector or mediator?" Circulation Research, vol. 96, no. 1, pp. 6-8, 2005.

[109] R. Ross, "Atherosclerosis-an inflammatory disease," The New England Journal of Medicine, vol. 340, pp. 115-126, 1999.

[110] S. M. Schwartz, "Smooth muscle migration in atherosclerosis and restenosis," Journal of Clinical Investigation, vol. 100, no. 11, pp. S87-S89, 1997.
[111] C. Bauters and J. M. Isner, "The biology of restenosis," Progress in Cardiovascular Diseases, vol. 40, no. 2, pp. 107116, 1997.

[112] P. Libby, D. Schwartz, E. Brogi, H. Tanaka, and S. K. Clinton, "A cascade model for restenosis: a special case of atherosclerosis progression," Circulation, vol. 86, no. 6, supplement, pp. III47-III52, 1992.

[113] P. Carmeliet, L. Moons, J. M. Stassen et al., "Vascular wound healing and neointima formation induced by perivascular electric injury in mice," American Journal of Pathology, vol. 150, no. 2, pp. 761-776, 1997.

[114] T. Asahara, H. Masuda, T. Takahashi et al., "Bone marrow origin of endothelial progenitor cells responsible for postnatal vasculogenesis in physiological and pathological neovascularization," Circulation Research, vol. 85, no. 3, pp. 221-228, 1999.

[115] T. Asahara, T. Murohara, A. Sullivan et al., "Isolation of putative progenitor endothelial cells for angiogenesis," Science, vol. 275, no. 5302, pp. 964-967, 1997.

[116] K. Ito, A. Hirao, F. Arai et al., "Reactive oxygen species act through p38 MAPK to limit the lifespan of hematopoietic stem cells," Nature Medicine, vol. 12, no. 4, pp. 446-451, 2006.

[117] W. Strawn, R. Richmond, and C. Ferrario, "A new understanding of atherosclerosis: the bone marrow response-tolipid hypothesis," in Heart Disease: Pathogenesis, Diagnosis and Treatment, pp. 183-188, 3rd World Congress on Heart Disease, Washington, DC, USA, 2003.

[118] W. B. Strawn and C. M. Ferrario, "Angiotensin II AT receptor blockade normalizes $\mathrm{CD} 11 \mathrm{~b}(+)$ monocyte production in bone marrow of hypercholesterolemic monkeys," Atherosclerosis, vol. 196, no. 2, pp. 624-632, 2008.

[119] D. Fukuda and M. Sata, "The renin-angiotensin system: a potential modulator of endothelial progenitor cells," Hypertension Research, vol. 30, no. 11, pp. 1017-1018, 2007.

[120] L. A. Cassis, D. L. Rateri, H. Lu, and A. Daugherty, "Bone marrow transplantation reveals that recipient AT1a receptors are required to initiate angiotensin II-induced atherosclerosis and aneurysms," Arteriosclerosis, Thrombosis, and Vascular Biology, vol. 27, no. 2, pp. 380-386, 2007.

[121] Y. Tsubakimoto, H. Yamada, H. Yokoi et al., "Bone marrow angiotensin AT1 receptor regulates differentiation of monocyte lineage progenitors from hematopoietic stem cells," Arteriosclerosis, Thrombosis, and Vascular Biology, vol. 29, no. 10, pp. 1529-1536, 2009.

[122] T. Yamada, T. Kondo, Y. Numaguchi et al., "Angiotensin II receptor blocker inhibits neointimal hyperplasia through regulation of smooth muscle-like progenitor cells," Arteriosclerosis, Thrombosis, and Vascular Biology, vol. 27, no. 11, pp. 2363-2369, 2007.

[123] H. Lu, D. L. Rateri, D. L. Feldman et al., "Renin inhibition reduces hypercholesterolemia-induced atherosclerosis in mice," Journal of Clinical Investigation, vol. 118, no. 3, pp. 984-993, 2008.

[124] H. Kato, J. Ishida, K. Nagano et al., "Deterioration of atherosclerosis in mice lacking angiotensin II type $1 \mathrm{~A}$ receptor in bone marrow-derived cells," Laboratory Investigation, vol. 88, no. 7, pp. 731-739, 2008.

[125] D. Fukuda, S. Enomoto, R. Nagai, and M. Sata, "Inhibition of renin-angiotensin system attenuates periadventitial inflammation and reduces atherosclerotic lesion formation," Biomedicine and Pharmacotherapy, vol. 63, no. 10, pp. 754761, 2009. 


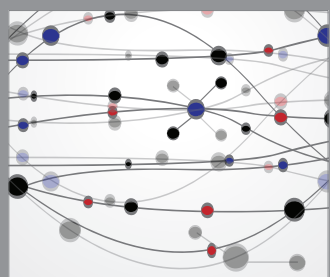

The Scientific World Journal
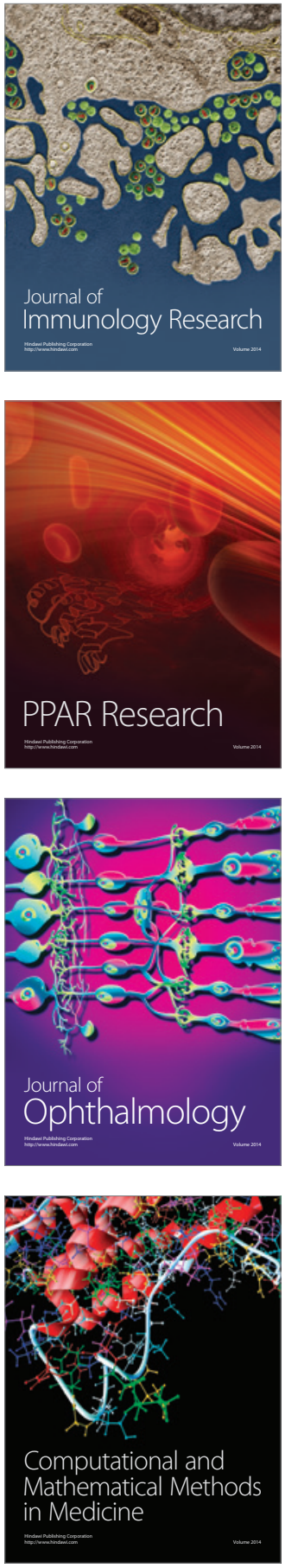

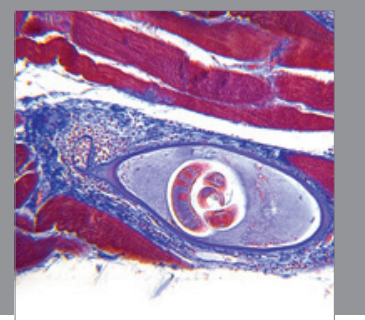

Gastroenterology

Research and Practice
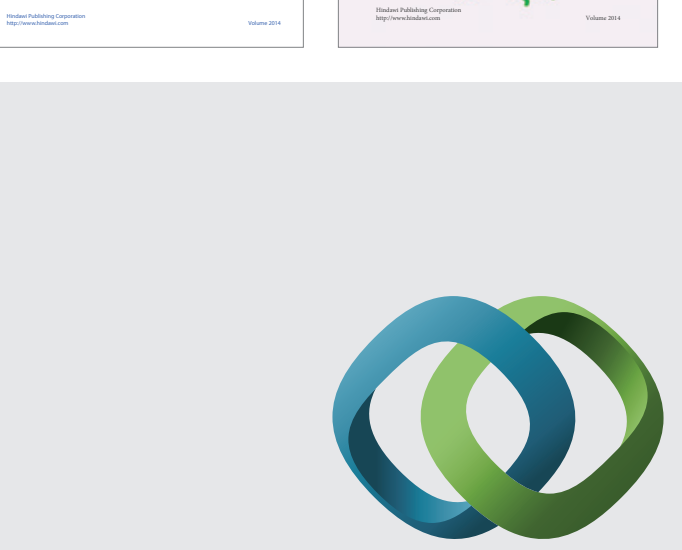

\section{Hindawi}

Submit your manuscripts at

http://www.hindawi.com
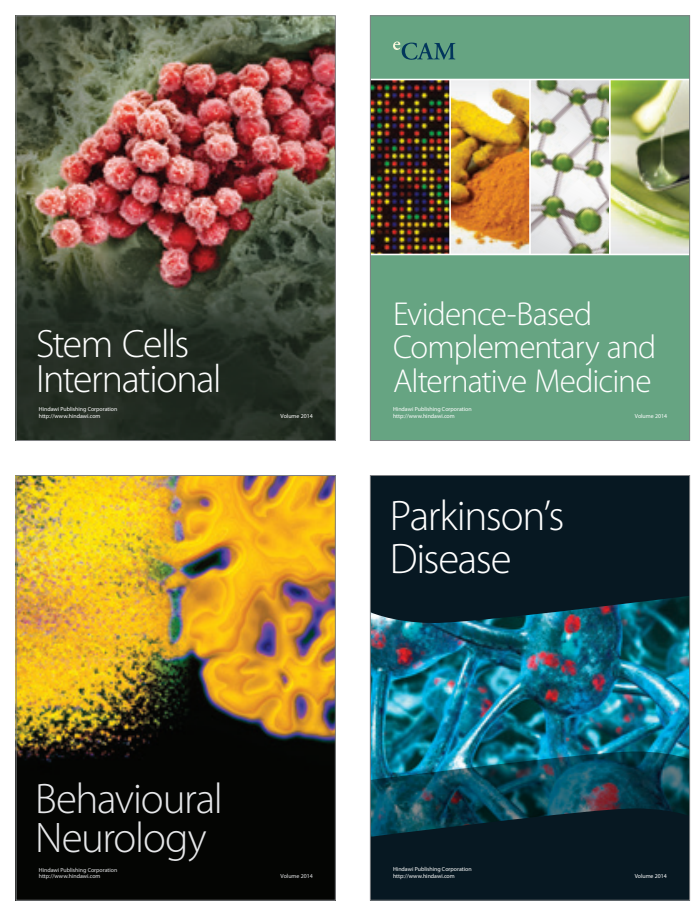

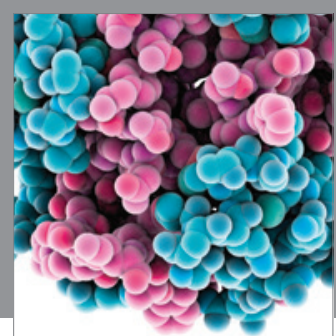

Journal of
Diabetes Research

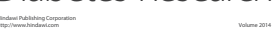

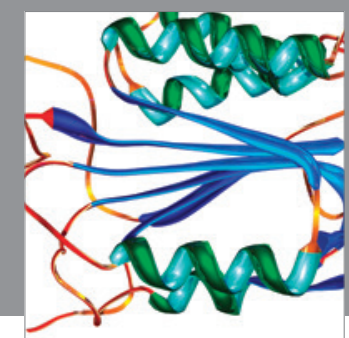

Disease Markers
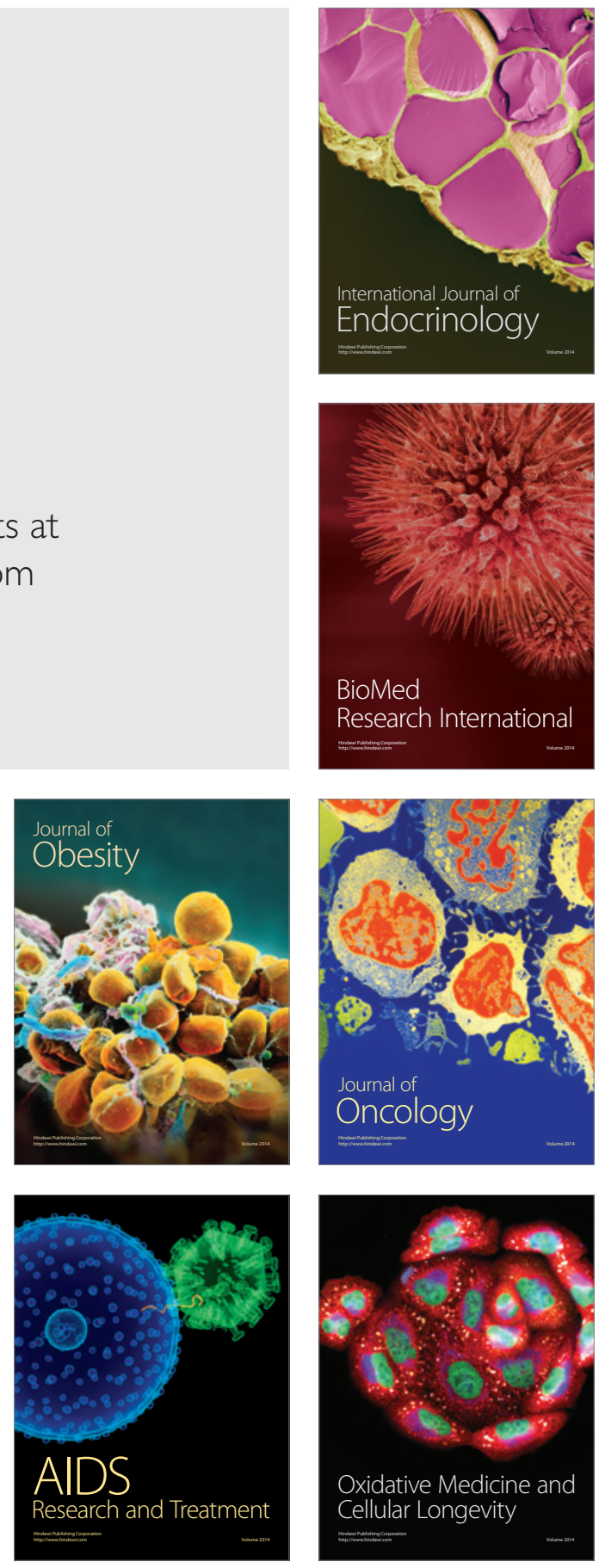